\title{
BMJ Open Associations of school tobacco policies and legislation with youth smoking: a cross-sectional study of Danish vocational high schools
}

\author{
Susan Andersen, ${ }^{1}$ Veronica Pisinger, ${ }^{1}$ Morten Hulvej Rod, ${ }^{2}$ Janne Tolstrup ${ }^{1}$
}

To cite: Andersen S, Pisinger V, Rod MH, et al. Associations of school tobacco policies and legislation with youth smoking: a cross-sectional study of Danish vocational high schools. BMJ Open 2019;9:e028357. doi:10.1136/ bmjopen-2018-028357

- Prepublication history and additional material for this paper are available online. To view please visit the journal (http:// dx.doi.org/10.1136/bmjopen2018-028357).

Received 4 December 2018

Revised 29 April 2019

Accepted 1 July 2019

Check for updates

(C) Author(s) (or their employer(s)) 2019. Re-use permitted under CC BY-NC. No commercial re-use. See rights and permissions. Published by BMJ.

${ }^{1}$ National Institute of Public Health, University of Southern Denmark, Copenhagen,

Denmark

${ }^{2}$ Health Promotion Research,

Steno Diabetes Center

Copenhagen, Gentofte, Denmark

Correspondence to

Dr Susan Andersen

sua@niph.dk

\section{ABSTRACT}

Background In vocational high schools, the prevalence of smoking is high (nearly $40 \%$ daily smoking in Danish vocational high schools). Schools are increasingly adopting school tobacco policies (STPS) and a national law on smoke-free school grounds has been implemented. Our objective was to explore the extent of STPs in vocational schools and examine the association of STPs and smokefree school grounds legislation with student smoking. Methods We used data from the cross-sectional Danish National Youth Study 2014, including 5013 vocational high school students ( $76 \%$ male) at 40 campuses. Implementation of STPs was measured by questionnaires to principals and field observations of smoking practices were conducted. Logistic regression models assessed whether STP characteristics were associated with students' current smoking (ie, daily and occasional) compared with non-current smoking. Negative binominal regression models assessed cigarettes per day among daily smokers.

Results Schools covered by the national law on smokefree school ground had more comprehensive STPs than schools not covered by the law. Student smoking was observed on $78 \%$ of campuses, with less visibility of smoking in schools covered by the national law $69 \%$ vs $83 \%$ ). Current smoking was lower for students attending a school covered by the national law $(\mathrm{OR}=0.86,95 \% \mathrm{Cl}$ 0.75 to 0.97 ). Students who attended schools that allowed teacher-student smoking were more likely to smoke $(\mathrm{OR}=1.13,95 \% \mathrm{Cl} 1.01$ to 1.27$)$.

Conclusions A law on smoke-free school grounds was associated with less current smoking in vocational high schools, while school norms that are supportive of teacherstudent smoking were associated with greater odds of current smoking. Visibility of student smoking was less prevalent at schools covered by the law on smoke-free school grounds; nevertheless, the visibility of smoking was high. Better enforcement or an extension of the current law on smoke-free school grounds is recommended.

\section{INTRODUCTION}

There is a marked negative social class gradient in cigarette smoking, with people of lower socioeconomic position smoking more. ${ }^{1}$ In Western countries, vocational education mostly attracts students from lower

\section{Strengths and limitations of this study}

- The study combined data from a survey to school principals, observations and whether schools were covered by smoke-free school grounds legislation with a student survey. A strength is that school data come from different sources and not from the student survey.

- The study will provide knowledge regarding the Danish law on smoke-free school grounds.

- The study population included young adults of lower socioeconomic background.

- Causal conclusions cannot be drawn in this cross-sectional study.

- The study may be limited in its generalisability to schools with low prevalence of student smoking and to other school types.

socioeconomic backgrounds ${ }^{2}$ and smoking is more persistent among students attending vocational education compared with general upper-secondary education. A Danish national survey showed that $37 \%$ of vocational high school students were daily smokers compared with $12 \%$ of general high school students. ${ }^{3}$ Vocational high school students might be exposed to a school context where the norms are such that smoking is considered acceptable and socially desirable. Therefore, schools with a large number of students who smoke may create a high-risk environment for starting and continuing smoking. As such, there is a need for knowledge on how high-risk schools can prevent and reduce smoking among students.

Schools have the potential to influence students' smoking behaviour through their social organisation and culture, as well as through the formal curriculum and policies. ${ }^{45}$ The dimensions as proposed by Bronfenbrenner $^{6}$ are the microsystem (the immediate settings in which people participate), mesosystem (interactions between these settings, eg, the relation between home 
and school), exosystem (the larger social system that affect people indirectly, eg, school policies) and macrosystem (the larger society, ie, the cultural, political and economic climate of the country). The most proximal influences of smoking are related to the everyday setting where the students interact directly with family, friends and school staff. ${ }^{6}$ From a policy perspective, the school environment can lead to changes in individual smoking behaviour by implementing school tobacco policies (STPs) and legislation. ${ }^{4}$ Furthermore, student commitment to school may be an influential factor for achieving positive effects of school policies. If students are not connected to the school and its staff and do not share the values of the school, it is unlikely that the school policy will affect student behaviour. ${ }^{8}$

Several studies have pointed to the importance of restricting smoking by comprehensive and clear prohibitions to both students and adults at school. ${ }^{9-11}$ Nevertheless, the evidence is inconclusive ${ }^{912}$ and most studies are conducted in schools with low smoking rates or among the youngest adolescents. ${ }^{713}$ A recent review ${ }^{14}$ examined the evidence of college antismoking policies and pointed to the need for studying community colleges and trade schools. If STPs work in settings like vocational schools, it could potentially narrow the inequality in smoking by socioeconomic status (SES). A systematic review ${ }^{15}$ among adults found strong evidence of a pro-equity effect from tobacco price increases, but inconclusive evidence that other interventions (eg, workplace smoking ban) were likely to reduce SES inequalities in smoking. Young people that live in families and communities where smoking is common are more likely to be exposed to social norms that reinforce smoking. ${ }^{16-18}$

On the other hand, structural interventions in the vocational school setting may present a window of opportunity for reducing the risk of smoking among a group of lower SES young people. Smoking policies in schools with high smoking rates may make a more important contribution to the reduction of smoking, because smoking is not yet denormalised.

The macrosystem is the outermost layer in the students' environment. ${ }^{6}$ Strong government policies and laws on tobacco may be important for tobacco control in schools. In 2012, a Danish law imposed a total smoking ban on school premises in educational institutions where the majority of students are younger than 18 years old. ${ }^{19}$ The minimum set by the national smoking legislation was no smoking at the school ground, which applies to all students, staff and visitors. No further restrictions were imposed, and the law does not prohibit smoking outside the school grounds. This amendment only prohibited smoking in vocational school institutions if the school share school premises with a general high school. This offers a possibility to study vocational high schools with and without the law on smoke-free school grounds. Such a comparison should consider that vocational schools that share premises with a general high school may enrol a different student population than vocational schools that do not share premises with a general high school. Vocational schools and general high schools are unified for practical reasons; some have canteen and other services in common, but the schools have separate management and teachers. Nevertheless, some vocational educations are placed in rural areas for space reasons (eg, agricultural colleges) or in former industrial buildings (eg, mechanics), while educations such as commerce and business service are easily situated in buildings that share premises with a general high school.

This paper adds to the existing research by examining STPs in vocational high schools that contain young adults and a less advantaged social group. The aim of this study was to (1) explore the extent of STPs in schools covered by the national law on smoke-free school grounds compared with schools not covered by the law and (2) examine the associations of school smoking policies and legislation on students' smoking behaviour.

\section{METHODS \\ Study design}

This cross-sectional study was based on surveys among the school management and students as well as field observations of smoking practices on the school ground and coding of whether the campus was covered by the national law on smoke-free school grounds.

\section{Participants and procedures}

Data come from the Danish National Youth Study, a national survey of high school students in Denmark conducted in $2014 .^{20}$ In the Danish educational system, young people from the age of about 16 can choose to continue from compulsory school into upper secondary education, either general or vocational education. Out of 12 invited vocational high schools, 10 schools participated. The schools were selected based on size and geographical location, in order to strengthen national representation. Schools in all regions of Denmark participated. The schools could select which classes that participated. Therefore, the sample was not representative of all vocational school students. ${ }^{20}$ For example, healthcare programmes and girls were under-represented. The 10 participating schools were organised in 40 individual school departments (campuses). Out of 7527 eligible students, 5168 students participated. Students not reporting their smoking status $(n=116)$ and without school identification number $(n=39)$ were excluded, leaving the total study population on 5013 students. Data collection included student questionnaire, principal questionnaire and field observations. Students answered a web-based questionnaire in class. The questionnaire for school principals was developed to gain information on the rules and general practice of schools when dealing with students' health-related behaviour.

A total of 40 department heads were invited to answer the school principal questionnaire and 38 completed the survey. Field observations on smoking practices on the 
Table 1 STP dimensions and study items

\begin{tabular}{ll}
\hline STP dimension & Study items \\
\hline $\begin{array}{l}\text { Comprehensiveness } \\
\text { (or lack of } \\
\text { comprehensiveness) }\end{array}$ & $\begin{array}{l}\text { Smoke-free school grounds which applies to both students, staff and visitors in school (the national } \\
\text { law) } \\
\text { Teachers are allowed to smoke with students } \\
\text { Students are allowed to take smoke breaks during (some) classes } \\
\text { The campus has smoking cessation support to the students } \\
\text { Regular procedure to inform students about existing smoking cessation service }\end{array}$ \\
$\begin{array}{ll}\text { Degree of formality } \\
\text { School covered by national law on smoke-free school grounds which means that official approval has } \\
\text { been opposed on the school management and school board. } \\
\text { The school has official approved an antitobacco policy }\end{array}$ \\
\begin{tabular}{ll} 
Enforcement & Consequences for breaking smoking rules (target: students) \\
Consequences & 'No Smoking' signs \\
Communication & National law on smoke-free school grounds and school-imposed policy components \\
\hline Level of &
\end{tabular} \\
\hline implementation &
\end{tabular}

STP, school tobacco policy.

school campus were carried out by two research assistants. Thirty-six campuses were visited for one whole or half a school day including breaks. The research assistants completed a 'walk-around' of the school ground to capture student smoking, tobacco sale and signs to prohibit smoking at school grounds. The observations were filled in a predefined observation manual.

\section{Measures}

\section{School tobacco policy}

We operationalised STPs based on the framework as suggested by Galanti et a ${ }^{\ominus}$ (table 1 ).

It was researcher coded whether schools were covered by the national law on smoke-free school grounds. Smoking at vocational high schools is prohibited if the school shares address with a general high school. The minimum set by the law is no smoking at the school premises, which applies to all students, staff and visitors. One researcher checked addresses to determine if the vocational high school was located next to a general high school and coded whether the campuses were covered by the national law on smoke-free school grounds (yes/no).

Principals completed a questionnaire and were asked if teachers were allowed to smoke with students (yes/ no), if students were allowed to take smoke breaks during lessons (yes/some classes/no), if there was consequences for breaking smoking rules (yes/no), if the campus offer assistance to smoking cessation (always or sometimes/not anymore/never) and if those who offer smoking cessation services had a regular procedure to inform students about the smoking cessation service (yes/no).

Field observations were used to collect data on tobacco sale and 'No smoking' signs. The observational checklist captured occurrence of tobacco sales on school ground for example, in the canteen (yes/no), whether students were smoking (yes, on the entire school ground/yes, in restricted smoking areas/no) and whether there were 'No smoking' signs on the school ground (yes/no).
Visibility of student smoking

The observational checklist captured whether students were smoking (yes, on the entire school ground/yes, in restricted smoking areas/no).

\section{Current smoking}

Students were asked what statement best described their current smoking status. We dichotomised this into daily or occasional smokers versus non-smokers (never or ex-smoker). Daily smokers were asked how many cigarettes they smoke daily.

\section{Covariates}

Students were asked to report their sex, birthday and birth year (from which age in years was calculated and categorised into 15-17 years, 18-24 years and $>24$ years) and perceived ethnicity (Danish/Danish and other/ non-Danish). Students were also asked about having parents who smoke (mother, father or stepparents), having siblings who smoke and the quality of relationships with their parents. The latter was assessed by the ease of communication through a Danish version of a question developed for the Health Behaviour in Schoolaged Children surveys: 'How easy is it for you to talk to the following persons about things that really bother you?'. A checklist of close people including 'father' and 'mother' was then given, with the response options of 'very easy', 'easy', 'difficult', 'very difficult' and 'don't have or don't see this person', on which a binary variable reflecting very easy or easy communication with mother or father was constructed..$^{21} 22$

Type of vocational education was categorised into the four main subject areas of the Danish vocational school system: 'Care, health and pedagogy', 'Administration, commerce and business service', 'Food, agriculture and hospitality' and 'Technology, construction and transportation'. 


\section{Statistical analysis}

Descriptive analyses were performed to determine the prevalence of tobacco policies at the school level in total and by schools covered by the national law on smoke-free school grounds.

We used logistic regression models to assess whether the variables were associated with students' current smoking compared with non-current smoking. OR and 95\% CI and $p$ values were reported for each variable.

To assess the associations with cigarettes smoked per day, we used negative binominal regression models and $P$ values were reported for each variable. Mean number of cigarettes and their corresponding 95\% CI were reported for each level of the variables and calculated based on the following level of the confounders: men, aged 18-24, Danish, parents are smoking, siblings are smoking, high quality of parental relationships and type of vocational education=Technology, construction and transportation. For the number of cigarettes-analyses, we limited the sample to a subsample of daily smokers $(n=1944)$.

All analyses were adjusted for age, sex, ethnicity, parents' smoking, sibling's smoking, quality of parental relationships and type of vocational education. Crude (unadjusted) analyses are presented in online supplementary table 1 .

The analyses were performed with available data. The number of school campuses ranged from 36 to 40 . The calculated intraclass correlation coefficient (ICC) was 0.022 for a null model and 0.018 for a model adjusted for individual-level variables (age, sex, ethnicity, parents' smoking, siblings' smoking, quality of parental relationships and type of vocational education). We ignored the dependency among students within campus (i) because the estimated ICC was low and (ii) because of lack of power. Simulation studies recommend a minimum of 50 in the group-level to produce unbiased SEs. ${ }^{23}{ }^{24}$ As sensitivity analysis, we conducted multilevel analyses. We used a two-level model with students (level 1) nested within school (level 2), allowing for correlation between students from the same school.

Analyses were conducted in SAS V.9.4 (SAS Institute, Cary, North Carolina, USA).

\section{Patient and public involvement}

The study did not involve patients or public in the development of the research question and outcome measures, the design of the study or the recruitment to and conduct of the study. The dissemination of the results will include communication channels that will involve schools.

\section{RESULTS}

\section{Student population characteristics}

Of 5013 students, 1944 (39\%) smoked cigarettes daily and $921(18 \%)$ smoked cigarettes occasionally (table 2 ); in total, $57 \%$ of the students were current smokers. The average number of cigarettes smoked per day was 15.5 among daily smokers. Half of the students reported they
Table 2 Characteristics of the student population $(n=5013)$

\begin{tabular}{|lr}
\hline Age (years), $\mathrm{n}(\%)$ & \\
\hline $15-17$ & $2584(34)$ \\
\hline $18-24$ & $731(15)$ \\
\hline$>24$ & $3803(76)$ \\
\hline Male, $\mathrm{n}(\%)$ & \\
\hline Ethnicity, $\mathrm{n}(\%)$ & $287(6)$ \\
\hline Non-Danish & $328(7)$ \\
\hline Danish and other & $4286(87)$ \\
\hline Danish & \\
\hline Smoking status, $\mathrm{n}$ (\%) & $1944(39)$ \\
\hline Daily & $921(18)$ \\
\hline Occasionally & $624(12)$ \\
\hline Ex & $1524(30)$ \\
\hline Never & $15.5(9.6)$ \\
\hline Number of cigarettes smoked per day, mean (SD)* & $2521(50)$ \\
\hline Parents who smoke, $\mathrm{n}$ (\%) & $1596(32)$ \\
\hline Siblings who smoke, $\mathrm{n}$ (\%) & $3692(74)$ \\
\hline High quality of parental relationships & \\
\hline Type of vocational education & $104(2)$ \\
\hline Care, health and pedagogy & $337(15)$ \\
\hline Administration, commerce and business service & $368(7)$ \\
\hline Food, agriculture and hospitality & \\
\hline Technology, construction and transportation & \\
\hline
\end{tabular}

*Only students who smoke daily was included.

had parents who smoke, while $32 \%$ had siblings who smoke.

The vocational schools that shared premises with a general high school had fewer students in the 'technology, construction and transportation' area than schools that did not share premises with a general high school $(71 \%$ vs $78 \%$; data not shown).

\section{School tobacco policies characteristics}

Fewer schools covered by the law did allow teachers to smoke with their students smoking $(41 \%$ vs $67 \%)$ and students to have smoke breaks during class $(47 \%$ vs $71 \%)$ and fewer had sales of cigarettes $(29 \%$ vs $6 \%)$ than schools not covered by the law (figure 1 ). The percentage of schools with smoking cessation support and sanctions were equal for schools with and without the law. The majority had sanctions for breaking the smoking rules, whereas about one third offered smoking cessation services (figure 1).

\section{School tobacco policies and smoking behaviour}

Students were less likely to smoke if they attended a school covered by the national law on smoke-free schoolgrounds (OR=0.86, 95\% CI 0.75 to 0.97) (table 3). Students were more likely to smoke if they attended a school where teachers were allowed to smoke together with the students $(\mathrm{OR}=1.13,95 \% \mathrm{CI} 1.01$ to 1.27$)$. Smoke 
Students are allowed to take smoke breaks during (some) classes

Teachers are allowed to smoke with students Sale of cigarettes
Smoking cessation support
Consequences for breaking smoking rules

"No smoking" signs

- Schools covered by the national law

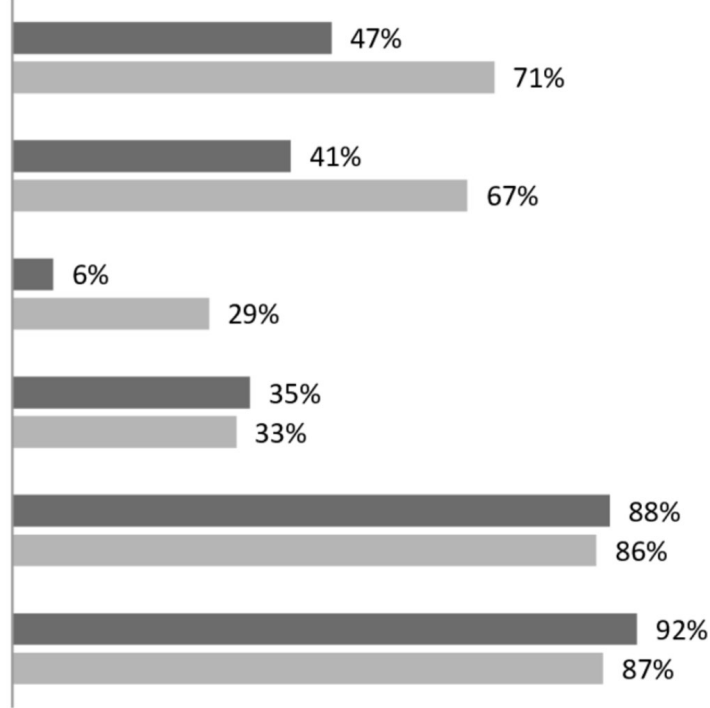

- Schools not covered by the national law

Figure 1 Prevalence of STP dimensions by vocational high schools with and without the Danish law on smoke-free school grounds. STP, school tobacco policy.

breaks, sanctions and sale of cigarettes were not associated with current smoking status (table 3 ).

Daily smokers smoked more cigarettes if they attended a school that allowed smoke breaks during class compared with prohibited smoke breaks (table 3). Daily smokers smoked less cigarettes if they attended a school with sanctions and if they attended a school that had regular procedure to inform students about existing cessation support compared with schools without any of these procedures (table 3).

Signs with 'No smoking' were associated with less current smoking and fewer cigarettes smoked.

\section{Smoking visibility on school ground and smoking behaviour}

Students were observed smoking on $78 \%$ of campuses (table 3). Campuses covered by the national law had less visibility of student smoking compared with campuses not covered by the law $(69 \%$ vs $83 \%$, see online supplementary figure 1 ).

Visibility of cigarette use on the entire school ground was associated with higher odds of current smoking $(\mathrm{OR}=1.21,95 \%$ CI 1.04 to 1.40$)$ compared with schools with no visibility of smoking; no association was found for visibility of smoking in restricted smoking areas (table 3). No association was found between smoking visibility and number of cigarettes among smokers.

\section{Robustness of results}

To evaluate the stability of our results, replications with multilevel models were conducted. As expected, the multilevel models produced wider CIs, but the parameter estimates did not differ from the main results using unilevel models.

\section{DISCUSSION}

This study examined dimensions of school-level tobacco policy on schools with and without a national law on smoke-free grounds and possible associations with youth smoking. Although all schools had an official approved tobacco policy, the majority of schools allowed teachers to smoke with students and students could have smokebreaks during lessons. Schools that were subject to the national law had more comprehensive STPs. Overall, our results point to the importance of a legislation for smokefree schools and suggest that permission of teachers smoking with students increase the smoking prevalence.

We found that schools covered by the national law had fewer smoking students, although the smokers did not smoke fewer cigarettes. Interestingly, students smoked fewer cigarettes at schools that had regular procedure to inform the students about existing smoking cessation service. However, only one-third of the schools reported smoking cessation support, regardless of the national law. A perspective that conceptualises smoking cessation support as a distinct part of STPs may be necessary in schools with high daily smoking prevalence to accommodate nicotine dependence ${ }^{25}$ and easy access to tobacco treatment services. ${ }^{26}$

Our findings regarding teachers' smoking with students underscores that STPs were not restrictive. The social learning theory ${ }^{27}$ and several studies emphasise the importance of teachers as social role models; this applies also to students in upper-secondary education. ${ }^{28}{ }^{29}$ Considering that schools covered by the law on smoke-free school grounds in lesser extent allowed teacher-student smoking than campuses not covered by the law, this legislation seems promising for implementing more comprehensive STPs. We also identified that the law on smoke-free school grounds seems 
Table 3 Dimensions of school tobacco policies and practice associated with smoking behaviour

\begin{tabular}{|c|c|c|c|c|c|}
\hline & $\begin{array}{l}\text { Campus } \\
\mathrm{N}(\%)\end{array}$ & $\begin{array}{l}\text { Current smoking* } \\
\text { OR }(95 \% \mathrm{Cl})\end{array}$ & $P$ value & $\begin{array}{l}\text { Daily cigarettes Mean } \\
(95 \% \mathrm{Cl}) \dagger\end{array}$ & $P$ value \\
\hline \multicolumn{6}{|c|}{ School tobacco policy } \\
\hline \multicolumn{6}{|c|}{ National legislation } \\
\hline \multicolumn{6}{|c|}{$\begin{array}{l}\text { The school is covered by Danish law on smoke-free } \\
\text { school grounds }\end{array}$} \\
\hline Yes & $17(43)$ & $0.86(0.75$ to 0.97$)$ & 0.016 & $16.1(15.3$ to 16.9$)$ & 0.67 \\
\hline \multicolumn{6}{|c|}{ The school has official approved a tobacco policy } \\
\hline Yes & $37(97)$ & - & & - & \\
\hline No & $0(0)$ & - & & - & \\
\hline Missing & $1(3)$ & - & & - & \\
\hline \multicolumn{6}{|c|}{ Comprehensiveness } \\
\hline \multicolumn{6}{|c|}{$\begin{array}{l}\text { Students are allowed to take smoke breaks during } \\
\text { (some) classes }\end{array}$} \\
\hline Yes & $23(61)$ & $0.94(0.83$ to 1.07$)$ & 0.38 & $16.4(15.6$ to 17.3$)$ & 0.003 \\
\hline No & $15(39)$ & 1 & & $15.2(14.3$ to 16.1$)$ & \\
\hline \multicolumn{6}{|c|}{ Sale of cigarettes on campus } \\
\hline Yes & $7(19)$ & $1.00(0.86$ to 1.17$)$ & 0.98 & 16.7 (15.6 to 17.9$)$ & 0.62 \\
\hline No & $30(81)$ & 1 & & 15.8 (15.0 to 16.6$)$ & \\
\hline
\end{tabular}

The school has smoking cessation support to the students

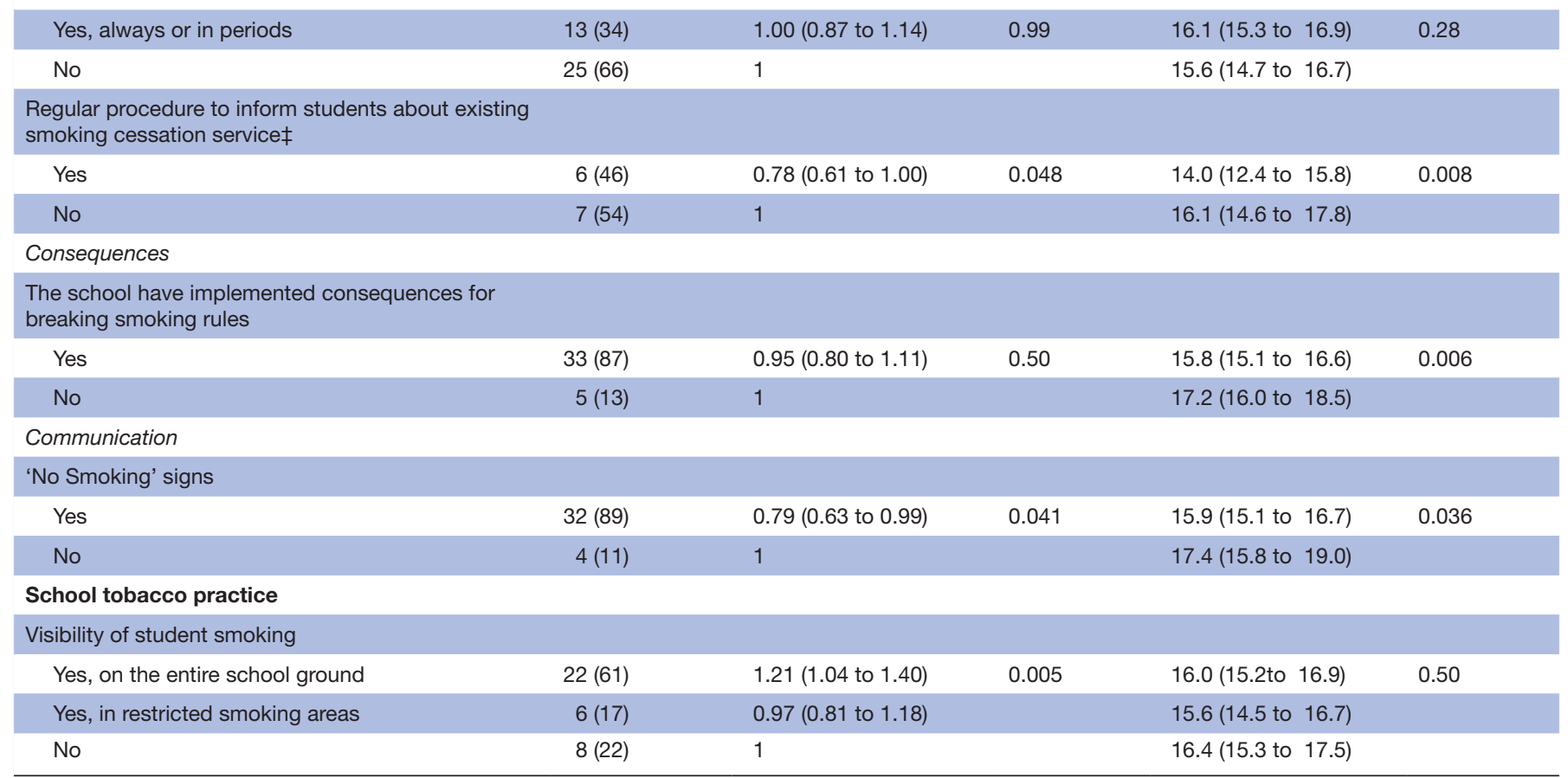

Analyses are adjusted for age, sex, ethnicity, parents' smoking, siblings' smoking, parental relationships and type of vocational education.

*Logistic regression analysis, with not current smoking as reference category (number of students=4716).

†Negative binomial regression analysis, only daily smokers who reported number of daily cigarettes was included (number of students=1870).

$\ddagger$ Among students who were enrolled in schools that offered smoking cessation services.

to decrease the probability of smoking visibility at the entire school ground, and our findings suggested that visibility of students' smoking on the entire school grounds is associated with the probability of smoking. Several studies have shown that smoking at visible school locations is associated with experimenting with smoking. ${ }^{41130}$ Higher frequencies of 
observing others smoke might lead to greater perceptions that smoking is socially acceptable ${ }^{31}$ and students might feel social pressure to smoke. ${ }^{11}$ Nevertheless, visibility of smoking in restricted areas was not associated with current smoking.

Counter to our hypothesis, our results did not demonstrate an association between sanctions and the number of smokers. It is, however, easy for students to avoid sanctions because they are allowed to smoke outside the school ground or in designated smoking areas within the school premise. Still, sanctions were associated to the amount (ie, number of cigarettes smoked per day). This may be explained by the mechanisms that it may be inconvenient to go to the smoking areas and the students feared to get caught in smoking. ${ }^{11}$ Access to tobacco is also suggested as a factor in youth smoking; ${ }^{31}$ however, in our study, we found no association between sale of cigarettes at the school property and smoking behaviour. This is consistent with a study of Borders and colleagues ${ }^{32}$ that examined policies regarding the sales and distribution of cigarettes on college campuses. Still, the large number of students who smoke may increase the use of social methods to obtain cigarettes ${ }^{33}$; students may buy or get their cigarettes for free from other students in school.

\section{Limitations and strengths}

This study is subject to a number of limitations. First, the use of self-reported data for student smoking is a potential source of bias. Smoking behaviour may be under-reported due to socially desirable answering; ${ }^{34}$ however, this may not be a problem in this study because many students and teachers smoke. Second, the data were cross-sectional and it is not possible to make causal inferences from the noted associations. Third, it is possible that there are unmeasured differences in the characteristics of schools that are confounded with STPs. Due to the available data, we were not able to include comprehensive measures of neighbourhood, family and student characteristics, ${ }^{35}$ notably we lacked measures of SES and measures of the neighbourhood. In addition, the STP data included a limited range of items and we lacked information about how STPs were enforced at the schools. This is an important aspect of STPs ${ }^{9}$ and research of this would be highly relevant. Moreover, the STP was only measured by school managers. The measurement of STP would have been strengthening if student reports had been included. Finally, limitations in terms of power should be noted. The relatively small numbers of school units impeded multilevel analyses and this study should be replicated with more schools included. Further, results of this study may not be representative of vocational high schools in other countries and may not be generalisable to general high schools. Therefore, replicating findings in other countries and across youth educational institutions will be important.

Despite the identified limitations, this study is one of the first to collect data about STPs in a low SES study population that include young adults who have a very high prevalence of smoking. The study includes data from several different sources; data on school policy came from school managers, the national law was objectively measured, we observed school practices and included student questionnaire data on smoking behaviour.

\section{Implications}

Contrary to other school settings, smoking in vocational schools is not denormalised and STPs may make an important contribution to the reduction of smoking. It has been suggested that STPs should contain certain characteristics including comprehensiveness, enforcement and sanctions ${ }^{9}$ and a national legislation like the Danish law on smoke-free school grounds might fit well into this perspective. Our findings showed that schools covered by the law were more restrictive in their approach to teacher and student smoking compared with schools not covered by the law. However, schools covered by the law are characterised by proximity to a general high school, which might have a denormalisation effect in itself. Observations of students who smoked at the school ground suggest low enforcement. Moreover, smoking probably occurred off the school grounds which is shown in several studies. For example, a Dutch study that tested the effectiveness of outdoor school ground smoking bans at secondary schools found that smoking outside the school grounds occurred more often in the experimental condition than in the control condition. ${ }^{36}$ This suggest that STPs might cause a reversal effect when the students find alternative locations to smoke off the school grounds. ${ }^{11}$ In contrast, a study found that smoking bans on the school grounds combined with smoking ban in the immediate surroundings of the school are associated with less student smoking. ${ }^{37}$

The current national law on smoke-free school grounds might need to be extended to involve a total smoking ban during school-time and with it prohibit smoking at front of the school, including for example, the footway right outside the school ground. Such an enhancement could potentially benefit low SES schools with high rates of smoking. Future research that exploits more comprehensive measures on STP, for example enforcement policies, would be helpful for addressing the shortcomings in the law.

\section{CONCLUSION}

Our study extends previous work on STPs by studying a low SES student population that includes young adults. Schools covered by the national law on smoke-free school grounds did to a lesser extent allow teacher-student smoking and smoking breaks. Moreover, visibility of smoking was less prevalent. Still, more effective enforcement of the current legislation is needed. Our results indicate that the national law on smoke-free school grounds was associated with less current smoking. Conversely, the law was not associated with the quantity of cigarettes. However, these findings are not conclusive and more research, for example longitudinal data, is needed to draw causal inference.

Acknowledgements The authors are grateful to the school managers and students who volunteered to participate in the Danish National Youth Study 2014. 
We thank the research assistants who supported the research process by their participation in observations and data collection.

Contributors All authors (SA, VP, MHR, JST) designed the study. VP collected the observation data. SA carried out the data analysis and prepared the first draft of the manuscript. JST contributed to the statistical analyses. All authors contributed to the writing of the manuscript and approved the final manuscript.

Funding This research was supported by TrygFonden (Denmark).

Disclaimer The funders had no role in study design, data collection and analysis, decision to publish or preparation of the manuscript.

Competing interests None declared.

Patient consent for publication Not required.

Ethics approval Ethics approval is not necessary under Danish law as this study did not include human biological material. The Danish Data Protection Agency approved the data collection and that all national confidentiality and privacy requirements were met (J. No. 2013-54-0526). Coordinators at the schools gave oral information about the study and the written information made available to the students clearly stated that participation in the study was voluntary and that responses would be treated confidentially. By participating they gave consent that their data could be used for research.

Provenance and peer review Not commissioned; externally peer reviewed.

Data sharing statement № additional data available.

Open access This is an open access article distributed in accordance with the Creative Commons Attribution Non Commercial (CC BY-NC 4.0) license, which permits others to distribute, remix, adapt, build upon this work non-commercially, and license their derivative works on different terms, provided the original work is properly cited, appropriate credit is given, any changes made indicated, and the use is non-commercial. See: http://creativecommons.org/licenses/by-nc/4.0/.

\section{REFERENCES}

1. Huisman M, Kunst AE, Mackenbach JP. Inequalities in the prevalence of smoking in the European Union: comparing education and income. Prev Med 2005;40:756-64.

2. Cedefop. Vocational education and training in Denmark. European centre for the development of vocational T. Luxembourg: Publications Office of the European Union, 2012.

3. Bendtsen P, Mikkelsen SS, Tolstrup JS. Ungdomsprofilen 2014 [Youth Profile 2014]. Copenhagen: National Institute of Public Health, University of Southern Denmark, 2015.

4. Sabiston CM, Lovato CY, Ahmed R, et al. School smoking policy characteristics and individual perceptions of the school tobacco context: are they linked to students' smoking status? J Youth Adolesc 2009;38:1374-87.

5. Shackleton N, Jamal F, Viner RM, et al. School-based interventions going beyond health education to promote adolescent health: systematic review of reviews. J Adolesc Health 2016;58:382-96.

6. Bronfenbrenner U. Ecological models of human development. In: Husén T, Postlethwaite N, eds. International encyclopedia of education. Oxford: Elsevier, 1994:1643-7.

7. Coppo A, Galanti MR, Giordano L, et al. School policies for preventing smoking among young people. Cochrane Database Syst Rev 2014:CD009990.

8. Bonell CP, Fletcher A, Jamal F, et al. Theories of how the school environment impacts on student health: systematic review and synthesis. Health Place 2013;24(Suppl C):242-9.

9. Galanti MR, Coppo A, Jonsson E, et al. Anti-tobacco policy in schools: upcoming preventive strategy or prevention myth? A review of 31 studies. Tob Control 2014;23:295-301.

10. Evans-Whipp TJ, Bond L, Ukoumunne OC, et al. The impact of school tobacco policies on student smoking in Washington State, United States and Victoria, Australia. Int J Environ Res Public Health 2010;7:698-710.

11. Schreuders M, Nuyts PAW, van den Putte B, et al. Understanding the impact of school tobacco policies on adolescent smoking behaviour: A realist review. Soc Sci Med 2017;183(Suppl C):19-27.

12. Evans-Whipp T, Beyers JM, Lloyd S, et al. A review of school drug policies and their impact on youth substance use. Health Promot Int 2004;19:227-34.
13. Kuipers MA, de Korte R, Soto VE, et al. School smoking policies and educational inequalities in smoking behaviour of adolescents aged 14-17 years in Europe. J Epidemiol Community Health 2016;70:132-9.

14. Bennett BL, Deiner M, Pokhrel P. College anti-smoking policies and student smoking behavior: a review of the literature. Tob Induc Dis 2017:15:11.

15. Hill S, Amos A, Clifford D, et al. Impact of tobacco control interventions on socioeconomic inequalities in smoking: review of the evidence. Tob Control 2014;23:e89-e97.

16. Jahnel T, Ferguson SG, Shiffman S, et al. Momentary smoking context as a mediator of the relationship between SES and smoking. Addict Behav 2018;83:136-41.

17. Paul CL, Ross S, Bryant J, et al. The social context of smoking: a qualitative study comparing smokers of high versus low socioeconomic position. BMC Public Health 2010;10:211.

18. Zhou L, Niu L, Jiang H, et al. Facilitators and barriers of smokers' compliance with smoking bans in public places: a systematic review of quantitative and qualitative literature. Int $J$ Environ Res Public Health 2016;13:1228.

19. Jarlstrup NS, Juel K, Pisinger $\mathrm{CH}$, et al. International approaches to tobacco use cessation programs and policy in adolescents and young adults: Denmark. Curr Addict Rep 2018;5:42-53.

20. Pisinger V, Mikkelsen SS, Bendtsen P, et al. The Danish National Youth Study 2014: study design, population characteristics and nonresponse analysis. Scand J Public Health 2017:1-9.

21. Levin KA, Shaw T, Candice C, et al. mother-child communication, father-child communication, and adolescent life satisfaction: A crosssectional multilevel analysis. Health Education 2010;110:152-68.

22. Rayce SL, Holstein BE, Kreiner S. Aspects of alienation and symptom load among adolescents. Eur J Public Health 2009;19:79-84

23. Maas CJM, Hox JJ. Sufficient Sample Sizes for Multilevel Modeling. Methodology 2005;1:86-92.

24. Moineddin R, Matheson FI, Glazier RH. A simulation study of sample size for multilevel logistic regression models. BMC Med Res Methodol 2007;7:34.

25. Kleinjan M, van den Eijnden RJ, Engels RC. Adolescents' rationalizations to continue smoking: the role of disengagement beliefs and nicotine dependence in smoking cessation. Addict Behav 2009;34:440-5.

26. Hahn EJ, Fallin A, Darville A, et al. The three Ts of adopting tobacco-free policies on college campuses. Nurs Clin North Am 2012;47:109-17.

27. Bandura A. Social foundations of thought and action. A social cognitive theory. Englewood-Cliffs, New Jersey: Prentice Hall, 1986.

28. Piontek D, Buehler A, Rudolph U, et al. Social contexts in adolescent smoking: does school policy matter? Health Educ Res 2008;23:1029-38.

29. Øverland S, Aarø LE, Lindbak RL. Associations between schools' tobacco restrictions and adolescents' use of tobacco. Health Educ Res 2010;25:748-56

30. Lovato CY, Zeisser C, Campbell HS, et al. Adolescent smoking: effect of school and community characteristics. Am J Prev Med 2010;39:507-14.

31. Alesci NL, Forster JL, Blaine T. Smoking visibility, perceived acceptability, and frequency in various locations among youth and adults. Prev Med 2003;36:272-81.

32. Borders TF, Xu KT, Bacchi D, et al. College campus smoking policies and programs and students' smoking behaviors. BMC Public Health 2005;5:74.

33. Meyers MJ, Delucchi K, Halpern-Felsher B. Access to tobacco among california high school students: the role of family members, peers, and retail venues. J Adolesc Health 2017;61:385-8.

34. Connor Gorber S, Schofield-Hurwitz S, Hardt J, et al. The accuracy of self-reported smoking: a systematic review of the relationship between self-reported and cotinine-assessed smoking status. Nicotine Tob Res 2009;11:12-24.

35. Aveyard P, Markham WA, Cheng KK. A methodological and substantive review of the evidence that schools cause pupils to smoke. Soc Sci Med 2004;58:2253-65.

36. Rozema AD, Hiemstra M, Mathijssen JJP, et al. Impact of an outdoor smoking ban at secondary schools on cigarettes, e-cigarettes and water pipe use among adolescents: an 18-month follow-up. Int J Environ Res Public Health 2018;15:205.

37. Piontek D, Buehler A, Donath C, et al. School context variables and students' smoking. Testing a mediation model through multilevel analysis. Eur Addict Re 2008;14:53-60. 